\title{
Practice for Self-Regulatory Learning using Google Forms: Report and Perspectives
}

\author{
Toshiyasu Kato *, Yasushi Kambayashi *, \\ Yasushi Kodama $^{\dagger}$
}

\begin{abstract}
This paper presents a study that supports students who reflect their own learning in a face-to-face class, and then reports the results. Typically we have implemented Web exercises by using Google Forms as the place for self-learning and continual reflections. We have performed the text mining to "Devised it" of the Web exercises. We have observed the transformation from mentally passive word "Do" to active word "Examine it". We report how the Google Forms motivates students' self-regulatory learning. Based on these findings, we also present a prospect for a lesson that draws out the subjectivity of students.
\end{abstract}

Keywords: Self-Regulatory Learning, Metacognition, Google Forms

\section{Introduction}

The promotion of the attitude for active learning is a recent focus in higher education [1]. However, many students cannot learn actively. The present study thus seeks to determine how to motivate students to engage in active learning.

In this paper, we report the educational improvement we achieved using information and communications technology (ICT). To convert students' attitude from passive learning to active learning, the study intended to create an environment that enables active learning without instructor intervention. The final target is the scenario in which the instructor takes only the role of supervising the students' learning. We conducted a practical approach using the following educational improvement method [2], described in detail in sections 3 to 6 .

(1) Setting of daily learning environment: We prepared an environment in which students can learn daily with a familiar portable terminal [3].

(2) Task to learn: We set questions that highlighted the thought process. They include descriptive questions and those with multiple answers. Students can perform self-evaluation, which is not graded.

(3) Learning management and reflection by student: To promote active learning among stu-

* Nippon Institute of Technology, Saitama, Japan

$\dagger$ Hosei University, Tokyo, Japan 
dents, we prepared a place for reflection where they can bring their portable terminals and self-study after classes. Further, based on the results of a previous research [2], we aimed to draw out the subjectivity of the students and activate existing knowledge as knowledge related to individual experience applicable to various situations, as described in section 7.

\section{Related Work}

Goda examined the relationship between homework and diary keeping for each lesson [4]. He observed that the combination of homework and diary keeping promotes self-regulatory learning; students become accustomed to self-study. However, students tended to stop studying when they complete their assignments. Moreover, the instructor has to control all the homework, and thus cannot manage many students.

Azevedo proposed employing an online tutor agent [5]. The students were expected to "learn positively" by setting individual targets. However, the opposite occurs when the instructor misjudges the volume of the exercises assigned and scheduling of lessons.

Dabbagh studied guided self-regulatory learning using a web learning environment [6]. The environment support the learning scheme in terms of time and contents. However, the instructor cannot deal with many students in this scheme. Therefore, the issue is to develop a tool that automatically finds the learning method appropriate for each student.

Colthorpe investigated the relation between the presence of self-reflection based on the material accessed and report date of submission via a learning management system (LMS) [7]. Students who reported reviewing lectures as a learning strategy were more likely to access the available online lecture recordings. However, higher access was associated with poorer academic performance. High academic performance was positively associated with early submission of intra-semester assessment tasks but negatively associated with both actual use and reported use of lecture recordings by students. Nonetheless, the use of an online test enables realistic feedback.

\section{Promotion of Self-Regulatory Learning by ICT}

For this approach, we assume that self-regulatory learning is required. Zimmerman defined self-regulatory learning as involving "processes that keep starting acknowledgment, feelings, and the action for [oneself] so that learners may achieve those targets" [8]. Self-regulatory learning includes three processes, namely, self-observation, self-judgments, and self-reactions [9]. This approach is used in the current study in designing the place where the students can engage in self-learning and reflection. We lent support to students who wanted to perform continuous learning by themselves.

Figure 1 shows the flow of the lesson and learning situation. Students complete online exercises prior to each class. They examine and consult with others if they have questions they cannot solve. They participate in the lesson after solving the assigned problem in their notebook. In class, they ask those questions to the instructor. Thus, students learn in a coordinated manner in the classroom. "Correct answer list" is a collection of data sent to the "grade machine." The instructor does not present the correct answers immediately; he/she gives students advice and hints through the learners' discussions. 


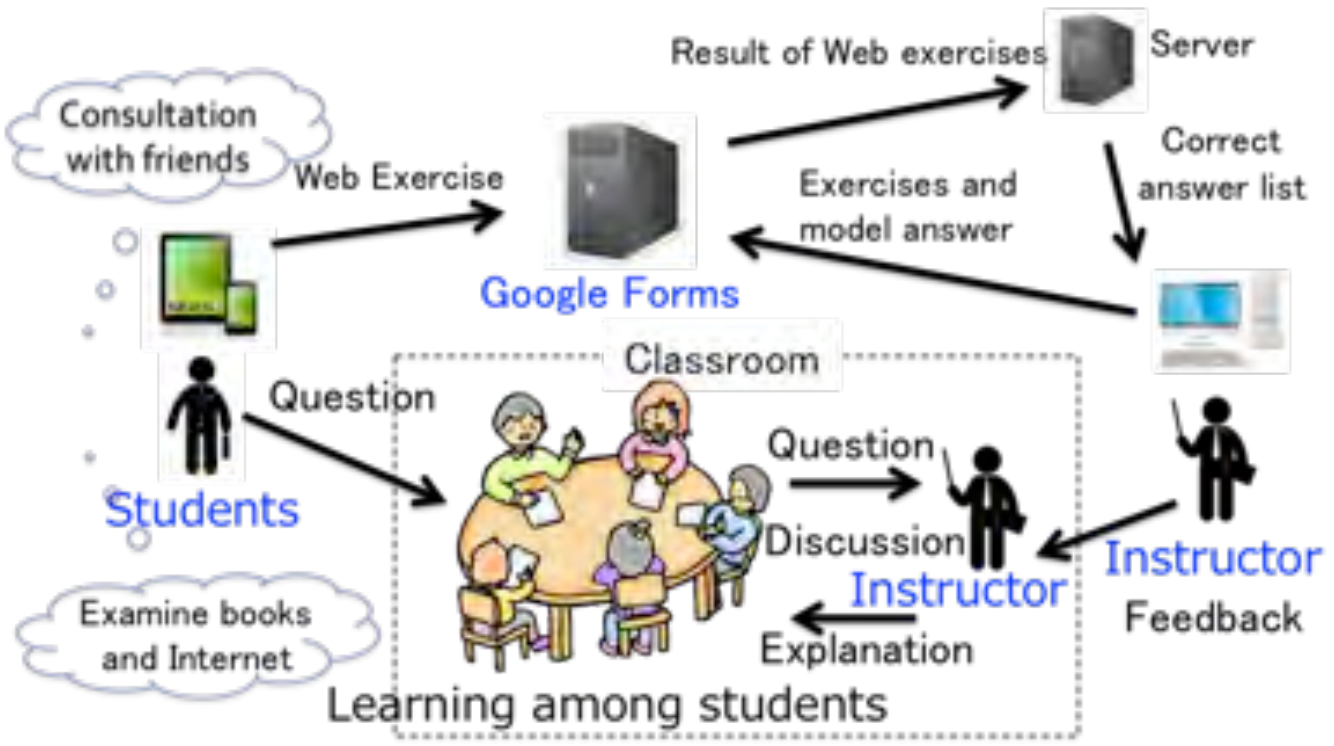

Figure 1: Self-learning and lesson flow using ICT

We performed the above lesson improvement using ICT at the Nippon Institute of Technology. Table 1 shows the target classes and course outline.

Table 1: Course outline

\begin{tabular}{l||l}
\hline Course name & $\begin{array}{l}\text { Base I of Sentence Ability Training } \\
\text { Improving academic literacy }\end{array}$ \\
Rejective & Required \\
$\begin{array}{l}\text { Number of instructors } \\
\begin{array}{l}\text { Number of students at the end } \\
\text { of the semester }\end{array}\end{array}$ & 533 students in spring 2015 \\
\hline
\end{tabular}

There are several advantages in using ICT for learning. The first is that a student can learn at his or her own time. We prepared the learning environment where the students can build their learning habits. The second is that a student can use familiar media. Modern university students are used to communicating with others using portable terminals [10]. Students are comfortable using portable terminals for learning. The third is that learning materials based on ICT can be designed more flexibly than printed materials. This approach leads us to use Google Form to make the exercise.

The use of LMS is gaining ground because it is suitable for piling-type learning contents. However, our approach focuses on the learning methods and experiences related to LMS. Therefore, we chose to use Google Forms as it provides the environment that enables us to change the exercises easily during the run of courses. Even instructors with no ICT expertise can use Google Forms. Tanaka et al. reported that Google Forms interfaces are more general than LMS, enabling convenient use for most students [11]. Their report supports our decision to use Google Forms. 


\section{Executing Web Exercises Using Google Forms}

\subsection{Outline of Web Exercise}

We prepared 13 exercises for 14 lessons (Table 2).

Table 2: Course outline

\begin{tabular}{cll}
\hline Exercise & Contents & Question \\
\hline \hline 1 & Honorifics & 20 \\
2 & Grammar & 41 \\
3 & Vocabulary & 30 \\
4 & Meaning & 20 \\
5 & Wording & 25 \\
6 & Written kanji & 50 \\
7 & Definition & 56 \\
8 & Opposite word 1 & 88 \\
9 & Opposite word 2 & 40 \\
10 & Kanji Reading & 100 \\
11 & Words of Japanese origin & 160 \\
12 & The same spelling 1 & 80 \\
13 & The same spelling 2 & 103 \\
\hline
\end{tabular}

One of the learning targets of the lesson is preparation for the "second level Japanese" achievement test. Thus, the exercise is composed according to the contents of the Japanese achievement test. We set the number of questions to a few, initially, and then we increased it as the semester proceeded. To promote the students" reflection, we included a "When grappling with the exercise, devise it" function at the end of the exercises. An example of Google Forms used in this study is shown in Figure 2.

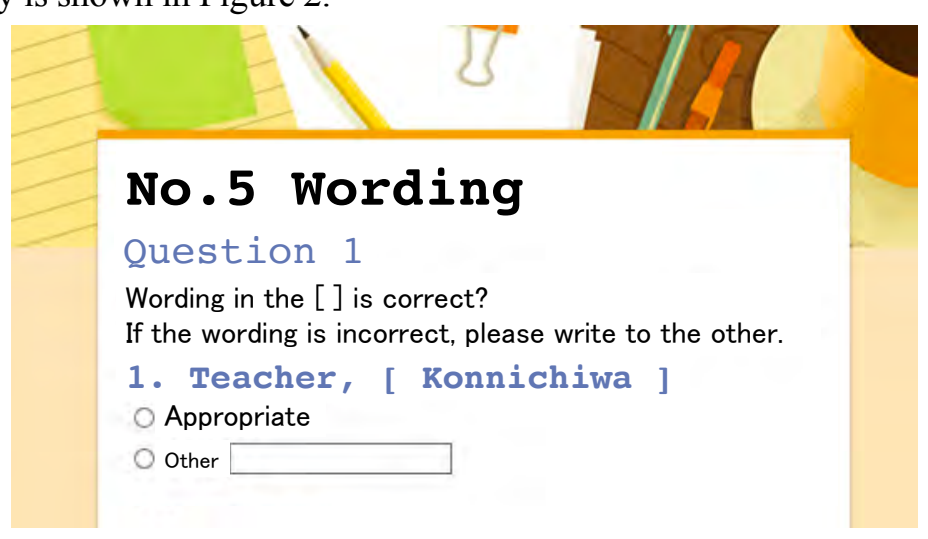

Figure 2: An example of Google Forms 


\subsection{Setting "Think" Questions}

An advantage of using ICT is that it can provide real-time feedback according to individual progress. Moreover, it helps students progress in the learning target in small steps. However, as we characterized the web exercise in this approach as a resource for learning, we did not decide to provide feedback in real time.

(1) "Choose" to "Think": We provide not only multiple-choice type questions but also those that make students deeply consider their responses.

(2) "Hit" to "Think": Multiple-choice type questions can be answered correctly even with only vague understanding. However, it is important that learning deepens students' understanding. Thus, we prepared all the choices to the common question. For instance, choices become 40 in 40 questions.

\subsection{Management of Learning Context}

The instructor manages the students' learning, as shown in Figure 3. A student who requests confirmation of the self-evaluation result can collate it with the result table.

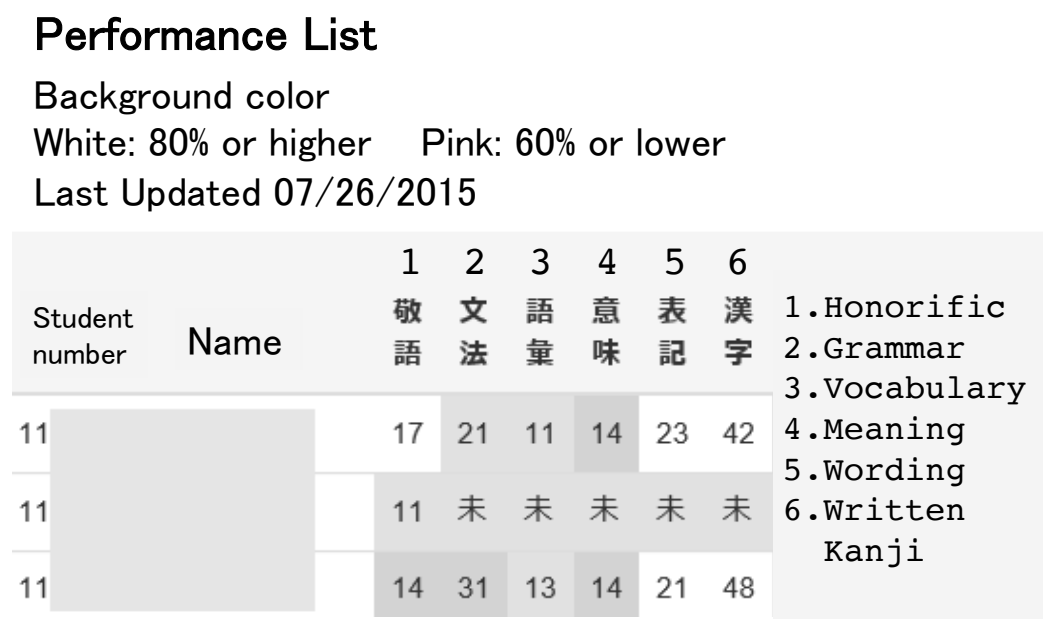

Figure 3: Students' Grades List

\section{Web Exercise: Approach and Arrival}

In the first half of the semester, $90 \%$ of the students accomplished the exercise. However, by the middle of the semester, the ratio dropped to $80 \%$. It decreased to $60 \%$ in the latter half of the semester (Figure 4). 


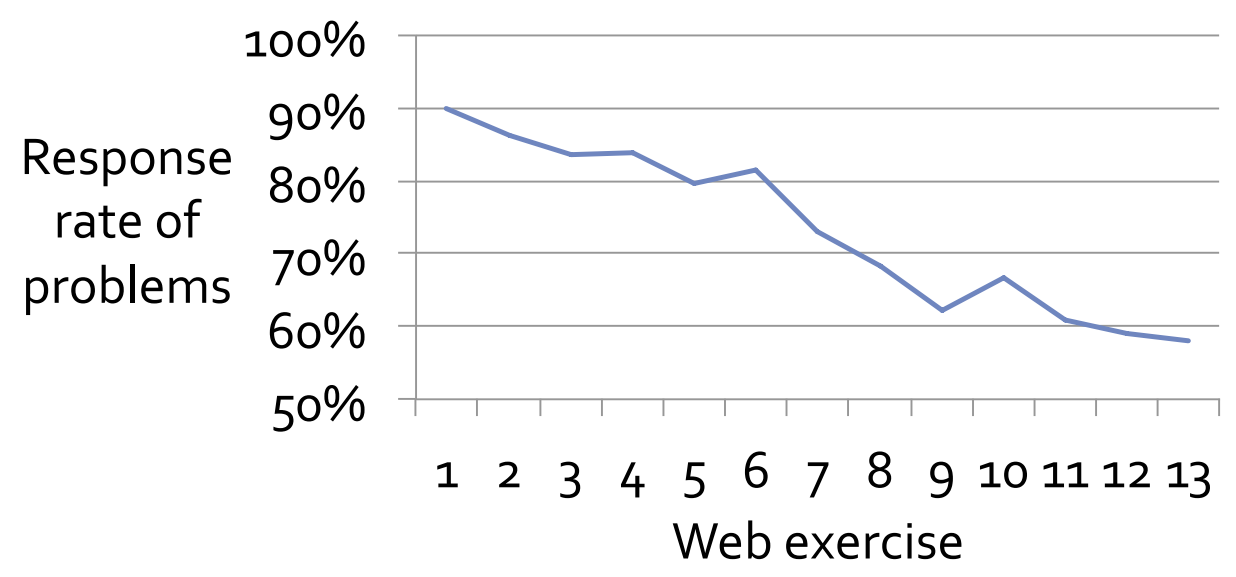

Figure 4: Transition of exercise executing rate

The decrease in the execution rate was expected. Students do not necessarily advance various problems according to schedule. We expect students to become conscious that they can achieve no advance from time to time. We expect them to devise methods of follow-up to the plan.

\section{Results}

We observed that each student continued learning and engaging in self-reflection. The students experienced the method of self-understanding through the learning management that supported self-regulatory learning. They continued to use the learning management and engaged with the exercises, as shown in section 4 . The number of students who passed the second-level Japanese achievement test was 0 last year; this year, 62 students passed.

Moreover, we observed that the students' learning methods and attitudes matured. We suggested to the students to retake the test when the correct answer rate of the exercise does not reach $80 \%$. The descriptions listed below are those students reported what they reported for the "Devised it" function. The description shows the shift in attitude from passive to active.

- I answered without examining anything. (5/17)

I wrote what I don't understand in my notebook. (7/8)

- I answered without seeing anything. I recalled it from memory. (5/18)

I used and examined the dictionary. (7/3)

- I could not understand the exercise even though I examined the textbook. $(5 / 21)$

I answered the exercise after discussing with a friend. (6/23) 
Figure 5 shows the text mining result for the "Devised it" function.

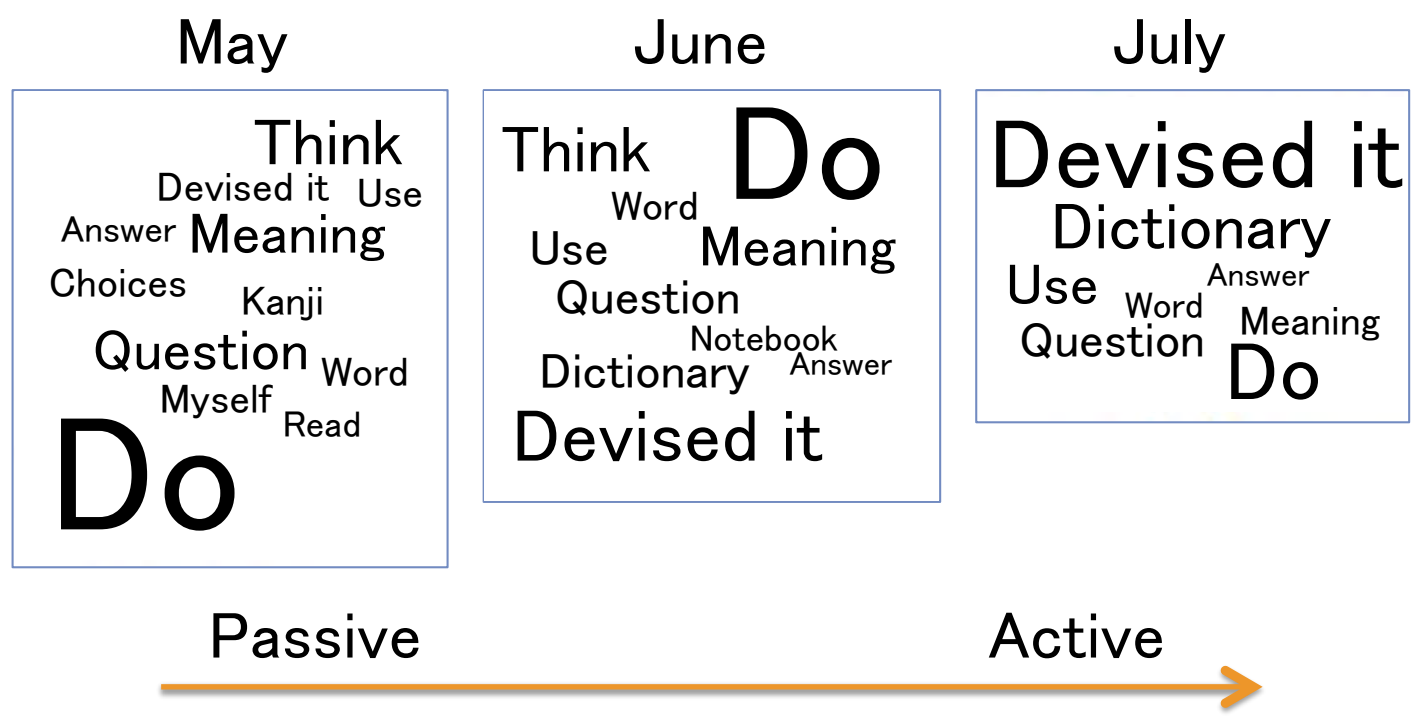

Figure 5: Result of text mining

In Figure 5, the size of the character corresponds to the appearance rate. In May, "Do" appeared in 53\% of responses, whereas "Examine it" in 15\%. In June, the appearance rates shifted: "Do," 36\%; "Examine it," 28\%. By July, the appearance rate of "Do" dropped to $18 \%$, whereas that of "Examine it" rose to 39\%. This trend corresponds with students' progress in the learning scheme. In May, students simply performed the given exercise. In June, they started to use dictionaries, examine word meanings, and select one meaning from various learning strategies. In July, problem accomplishment decreased, whereas the learning plot related to items being examined increased. "Examine it" in the learning plot increased, indicating that the learning plot "Examine it in the dictionary" is effective. This outcome may be attributed to the Japanese exercises that encouraged students to continue learning through trial and error.

\section{Proposal for In-Class Utilization of Google Forms to En- courage Self-Regulatory Learning}

Students who do not have experience in or ideas on learning methods tend to be stalled. We would like to consider ways to encourage students toward self-regulatory learning without or with minimal instructor management. Therefore, the following two points will be examined.

- The input of faculty members is minimized, and students participate actively in learning by themselves.

- Opportunities will be provided for students to explore and activate knowledge in connection with their past experiences.

In the lesson, we use diverse items under "things we have not mentioned so far," such as foreign television commercials, short sentences written in Japanese, problems of numerical rea- 
soning, as materials. Then, instructors and students share their interests and careful observations, as clues to understanding, while further exploring the language through interaction. The e-learning presented in this paper is also one of the materials, but as the place for interaction is not a classroom, it differs greatly in that there is no instructor during such interactions. Consequently, free recall and thought based on the students' individual experience is expected.

Examples of e-learning "contents for home learning" are shown in Figures 6 (assignment statement) and 7 (question sentence). Scrolling the screen to the bottom for students who cannot obtain clues shows reference information (Figure 8).

\title{
For home study
}

Please prepare your copy of the periodic table of elements. In it, choose a metal. Please write the element symbol and name in the order you like.

\author{
Ex.) Al aluminum
}

Figure 6: Example of initial "For home study" task assignment in the proposal

\section{Please write the reason for a metal of your no.1 choosing.}

Enter answer

\section{Please write your thoughts for a metal of your choosing.}

\section{Enter answer}

Figure 7: Example of later "For home study" task assignment 


\section{Ref. Info.}

\section{Ministry of education}

http://stw.mext.go.jp/series.html

Tokyo Electron

http://www.tel.co.jp/genso/periodic/

Periodic Table of the Elements

http://www.kagakudojin.co.jp/appendices/c12098/c12098poster.jpg http://www.kagakudojin.co.jp/book/b50191.html

Figure 8: Example of "For home study" reference information

The proposed example for home learning is "the metal you want." Students have generally examined the periodic table in the past at least once. However, they may have not engaged in the writing "explanation (fact)" and formulating "thought" from the viewpoint of "what I want." Freshmen may think that there is a correct answer. However, in this example, they do not know what is being asked. This unknown is the opportunity for learning.

We need to develop talents who will continue to learn throughout their life. Students will advance their learning in the field of specialization. Meanwhile, we need to explore broad knowledge to understand the fluidity of society as a whole in the context of difficulty in predicting the future. Thus, it is important to make students aware of active learning methods. This is also a major goal of the Learning Infrastructure subjects, and the tasks shown are designed to contribute to it.

\section{Summary}

We have constructed an environment based on Google Forms for students to engage in self-learning. The experiments showed that students changed their learning attitude from passive to active through the scheme. For the environment, we prepared exercises on Google Forms so that the students can learn the same theme but slightly different materials repeatedly for each lesson.

As a future task, from the view of self-adjustment learning, it is important to implement a mechanism for distinguishing between learning methods and reaching conditions with students approaching the same task. We also aim to examine the effect of creating a mechanism for preparing periodic summaries of review records, through which students' task execution and diverse learning styles can be analyzed. Additionally, we would like to consider how ICT could be utilized so that students become aware of their learning style and can develop their strengths and overcome their problems related to learning. 


\section{Acknowledgement}

This work was supported by Japan Society for Promotion of Science (JSPS), with the basic research program (C) (No. 15K01094), Grant-in-Aid for Scientific Research, as well as Google MOOC Focused Research Award.

\section{References}

[1] Ministry of Education, Culture, Sports, Science and Technology, "Central Education Council report"; http://www.mext.go.jp/component/b_menu/shingi/toushin/_icsFiles/afieldfile/2012/10/04/1 325048_1.pdf(In Japanese) (Accessed September 2, 2015)

[2] T. Kato, Y. Kambayashi, Y. Kodama, "A Report on the Practice Toward the Self-Regulatory Learning using Google Forms", International Congress on Advanced Applied Informatics (IIAI AAI 2016), LTLE-3, no.4, 2016.

[3] Japanese government statistics, "FY2013 youth Internet use environment Survey results of the (preliminary)", the Cabinet Office, 2014. (In Japanese)

[4] Y. Goda, M. Yamada, T. Matsuda, H. Kato, Y. Saito, H. Miyagawa, "Plan and Reflection of Self-regulated Learning. Perspectives of Outside Classroom Learning Hours and English Proficiency", Japan Society for Educational Technology Journal, vol.38, 2014, pp.77-80. (In Japanese)

[5] R. Azevedo, A.F. Hadwin, "Scaffolding self-regulated learning and metacognitionImplications for the design of computer-based scaffolds", Instructional Science, vol.33, no.5, 2005, pp.367-379.

[6] N. Dabbagh, A. Kitsantas, "Supporting self-regulation in student-centered web-based learning environments", International Journal on E Learning, vol.3, no.1, 2004, pp.40-47.

[7] K. Colthorpe, K. Zimbardi, L. Ainscough, S. Anderson, "Know thy student! Combining learning analytics and critical reflections to develop a targeted intervention for promoting self-regulated learning", Journal of Learning Analytics, vol. 2, no.1, 2015, pp.134-155.

[8] B.J. Zimmerman, D.H Shank editing, "Self-Regulating Learning Handbook", Kitaoji Shobo, 2014. (In Japanese)

[9] A. Bandura, "Social foundations of thought and action: A social cognitive theory", Englewood Cliffs NJ: Prentice Hall, 1986.

[10] T. Kitazawa, K. Sato, T. Akahori, "The Effect of Question Styles and Methods in Quizzes Using Mobile Devices on Student Motivation and Percentage of Correct Answers", Japan Society for Educational Technology Journal, vol.38, no.3, 2014, pp.193-209. (In Japanese)

[11] K. Tanaka, R. Suzuki, H. Yamazaki, “Attempt of Google Apps used as LMS”, Information Education Symposium 2013 Proceedings, 2013, pp.209-215. (In Japanese) 